\title{
Reversible Coma: A Rare Presentation of Spontaneous Intracranial Hypotension
}

\author{
Jodi L. Kashmere, Michael J. Jacka, Derek Emery, Donald W. Gross
}

\begin{abstract}
Background: Spontaneous intracranial hypotension (SIH) is a well-recognized neurologic disorder that typically presents with orthostatic headaches, low cerebral spinal fluid pressures and distinct abnormalities on magnetic resonance imaging. Methods: We present a case of a rare presentation of SIH. Results: A 49-year-old man presented with a two week history of orthostatic headaches that rapidly progressed to encephalopathy and coma, requiring intubation. Neuroimaging revealed abnormalities typical of SIH; diffusely enhancing pachymeninges, subdural fluid collections, and descent of the brain. Treatment with an epidural blood patch reversed his coma within minutes. Following a second blood patch, the patient became asymptomatic. No cerebral spinal leak could be identified on magnetic resonance imaging or on a nuclear medicine technetium cerebral spinal fluid flow study. At six month follow-up, he remained symptom free. Conclusion: The mechanism of coma in SIH is presumed to be compression of the diencephalon from downward displacement of the brain. Although it is very unusual for patients with SIH to present with coma, it is important to recognize since the coma may be reversible with epidural blood patches.
\end{abstract}

RÉSUMÉ: Coma réversible: un mode de présentation rare de l'hypotension intracrânienne spontanée. Introduction: L'hypotension intracrânienne spontanée (HIS) est un problème neurologique bien connu dont le mode de présentation clinique est caractérisé par des céphalées orthostatiques, une pression basse du liquide céphalorachidien et des anomalies caractéristiques à l'imagerie par résonance magnétique. Cas clinique: Nous présentons un cas dont le tableau clinique était inusité. Résultats: Un homme âgé de 49 ans a consulté pour des céphalées orthostatiques présentes depuis deux semaines, qui ont progressé rapidement vers une encéphalopathie et un coma nécessitant une intubation. La neuroimagerie a montré des anomalies typiques de l'HIS: un rehaussement pachyméningé diffus, des collections liquidiennes sous-durales et un déplacement vers le bas des structures cérébrales. Le traitement par colmatage sanguin épidural a résolu le coma en quelques minutes. Les symptômes ont disparu après un deuxième colmatage sanguin. Aucune fuite de LCR n'a pu être détectée à l'imagerie par résonance magnétique ou à l'étude de la circulation du LCR par le technetium. Six mois plus tard, le patient était toujours asymptomatique. Conclusion: Une compression du diencéphale par un déplacement du cerveau vers le bas est le mécanisme présumé du coma dans l'HIS. Bien qu'il soit inusité que les patients ayant une HIS présentent un coma, il est important de reconnaître cette entité parce que le coma peut être traité avec succès par colmatage sanguin épidural.

Can. J. Neurol. Sci. 2004; 31: 565-568

Spontaneous intracranial hypotension (SIH) is a wellrecognized neurologic disorder that typically presents with orthostatic headaches, low cerebral spinal fluid (CSF) pressures, and distinct abnormalities on magnetic resonance imaging (MRI). ${ }^{1}$ The clinical presentation is manifested mainly by postural headaches that resolve with recumbency. Other associated manifestations include: nausea, vomiting, visual loss, blurred vision, photophobia, diplopia from extraocular palsies, auditory disturbances, cranial nerve palsies, dizziness, interscapular pain, and radicular symptoms. ${ }^{1}$ The CSF usually shows opening pressure less than $60 \mathrm{~mm}$ of water, and may show increased protein, lymphocytosis, and/or xanthochromia. The typical MRI abnormalities include: diffuse enhancement of the pachymeninges, subdural fluid collections, descent of the brain with flattening of the pons against the clivus, low lying tonsils, decreased ventricle size, and downward displacement of the optic chiasm. ${ }^{1-3}$

Variable presentations of spontaneous intracranial hypotension have been identified. ${ }^{1}$ Patients can present with chronic daily headache, normal CSF pressure, or normal MRI.

From the Division of Neurology, Department of Medicine, (JLK, DWG); Department of Anesthesiology, Division of Critical Care, (MJJ); Department of Radiology and Diagnostic Imaging, Department of Biomedical Engineering, (DE); University of Alberta, Edmonton, Alberta, Canada.

ReCeived OCtober 3, 2003. ACCePted infinalform February 5, 2004 Reprint requests to: DWGross, 2E3.19 Walter C McKenzie Health Science Centre, University of Alberta, Edmonton, Alberta, Canada, T6G 2B7 
Case reports of unusual manifestations exist in the literature and consist of patients presenting with parkinsonism/ataxia, ${ }^{4}$ frontotemporal dementia, ${ }^{5}$ encephalopathy ${ }^{6,7}$ and coma. ${ }^{8,9}$ Although SIH is an extremely rare cause of coma, it is an important diagnosis to recognize because it is treatable. We report a patient who presented with orthostatic headaches rapidly progressing to encephalopathy and coma. The coma was rapidly reversible with treatment.

\section{Case history}

A 49-year-old man presented with orthostatic headache and confusion. He had been diagnosed with an oropharyngeal squamous cell carcinoma five months previously and treated with radical excision, neck dissection, and ongoing radiation therapy.

His orthostatic headache began following physiotherapy neck stretching two weeks before admission. His headache was severe, aching and localized to the occiput bilaterally. It resolved within minutes of lying flat. The headache was progressive over two weeks and the patient became acutely confused on the day of admission. He was unable to follow commands and was able to answer only yes or no. There were no focal neurological deficits on examination. A contrast enhanced CTscan of the brain revealed diffusely enhancing meninges and small subdural fluid collections. Investigations were undertaken to rule out carcinomatous and infectious meningitis. A lumbar puncture was performed (opening pressure not available) and revealed $13 \times 10^{6}$ white blood cells/litre (no differential), $183 \times 10^{6}$ red blood cells/litre, protein 1.02 grams/litre, glucose 2.7 millimoles/litre, xanthochromia, negative culture, inconclusive cryptococcal antigen, negative acid fast bacilli, and negative cytology. He was treated with broad-spectrum antibiotics for possible infectious meningitis. An electroencephalogram showed a mild diffuse disturbance of background.

On day two in hospital, the patient acutely deteriorated and was admitted to ICU with decreased level of consciousness, continuous hiccups, and vomiting. Repeat CT scan of the brain was interpreted as being consistent with diffuse cerebral edema. The patient was therefore treated with Mannitol with an improvement in his symptoms. Because of the recent history of malignancy, a meningeal biopsy was performed through a left frontal burr hole. The biopsy showed evidence of acute and chronic subdural hematomas but no evidence of inflammatory or malignant cells. Over the two days following the biopsy, the patient became progressively more drowsy (Glasgow coma scale 6), requiring intubation. An MRI of the head showed small bilateral subdural hematomas, narrowing of the ventricles, and "sagging" of the brain into the posterior fossa, with compression of the diencephalon (Figure 1a and 1b). On hospitalization day seven, a diagnosis of intracranial hypotension was entertained based on the imaging findings and the normal biopsy. A $20 \mathrm{ml}$ lumbar epidural blood patch was performed.

Within 15 minutes of the blood patch the patient became alert and was communicating with his family. Extubation was performed. The patient remained well for the subsequent 24 hours before becoming increasingly drowsy. Forty-eight hours after the first blood patch, another epidural blood patch was performed. Within minutes, the patient became more alert and was again communicating appropriately. He was intermittently mildly drowsy over the next two days but thereafter retained a normal level of consciousness with intact cognition. After the second epidural blood patch the postural headache was no longer present.

An MRI of the spine and a nuclear medicine technetium study were performed, after the patient had recovered, to try to identify a CSF leak. During the isotope injection, the opening pressure was measured to be 6 $\mathrm{mm} \mathrm{Hg}$ (44 $\mathrm{mm}$ of water). Both tests were normal and no further investigations were performed since the patient had fully recovered. The patient remained asymptomatic at six month follow-up and the imaging abnormalities had returned to normal (Figure $2 \mathrm{a}$ and $\mathrm{b}$ ).

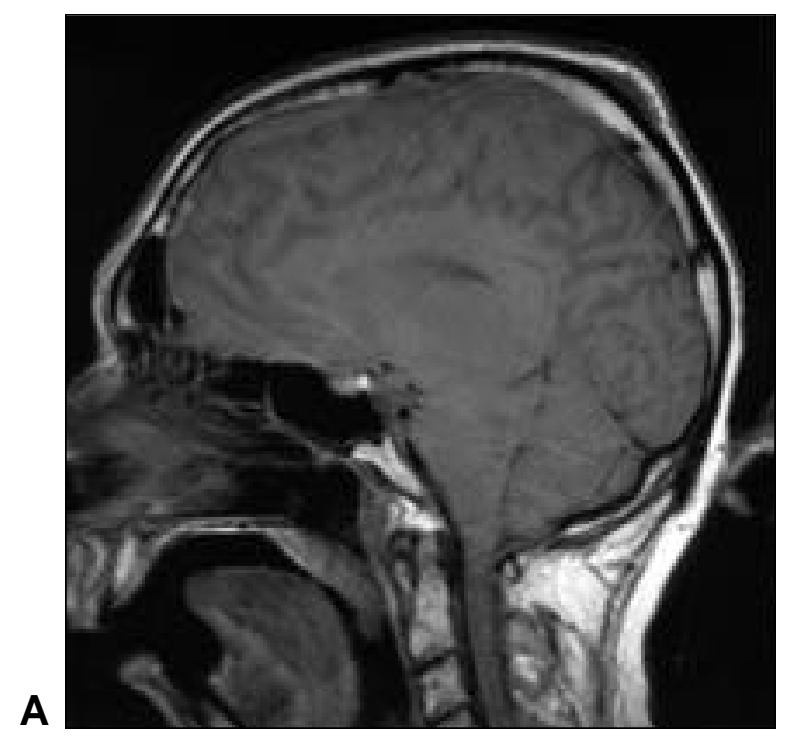

Figure 1a: Saggital T1 weighted MRI showing descent of the posterior fossa with compression of the midbrain, pons and medulla. (Prior to epidural blood patch).

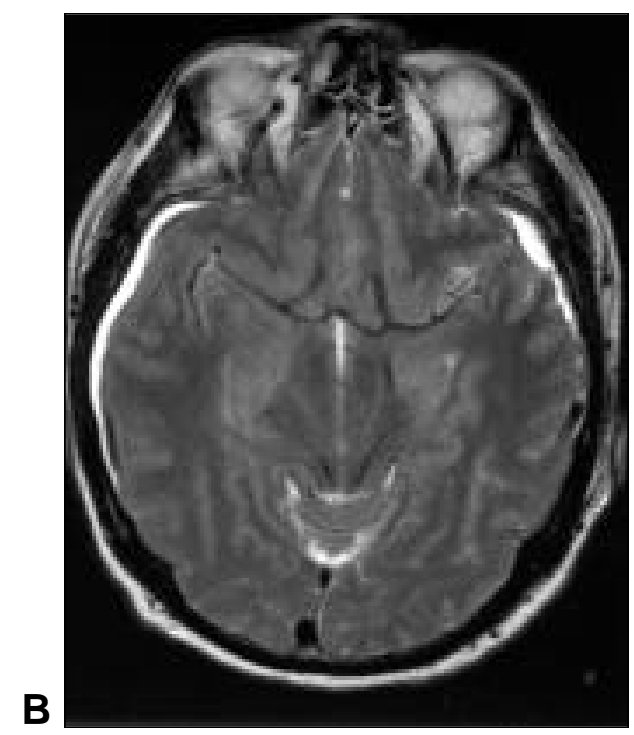

Figure 1b: Axial T2 weighted MRI showing bilateral chronic subdural hematomas and compression of the midbrain. (Prior to epidural blood patch). 


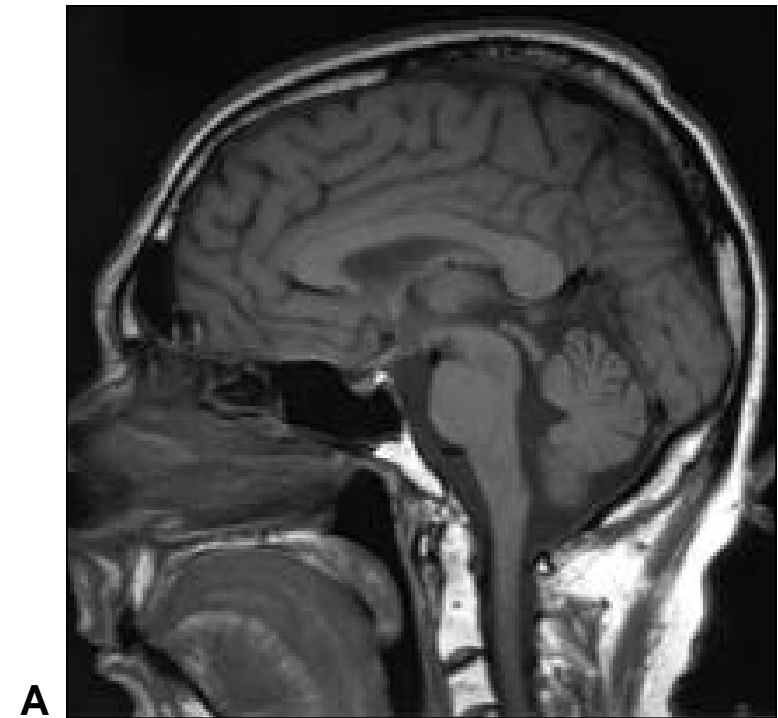

Figure 2a: Saggital T1 weighted MRI. Six months after resolution of the symptoms and the posterior fossa descent is no longer present.

\section{Discussion}

Spontaneous intracranial hypotension presenting as a rare cause of coma has been reported. ${ }^{8,9}$ In our patient, several factors led to a delay in making the correct diagnosis. First, the patient had a recent history of oropharyngeal malignancy and therefore it was crucial to rule out infection and/or malignancy. Unfortunately, the meningeal biopsy likely contributed to the patient worsening due to further loss of CSF. In addition, the postural nature of the headaches was not known to the physicians for the first few days. Third, the original imaging was incorrectly interpreted as being consistent with diffuse increased intracranial pressure. Although SIH was a well-recognized entity at our institution, the complex nature of this patient combined with the rare presentation of coma delayed the diagnosis. In retrospect, the history of orthostatic headache in combination with the typical MRI abnormalities of diffusely enhancing pachymeninges, subdural fluid collections, and evidence of brain descent, strongly supported SIH as the diagnosis. The CSF results were also consistent with the diagnosis of SIH and the symptoms began before the lumbar puncture. Even after the patient received the epidural blood patches and was recovering, the CSF pressure remained low $(6 \mathrm{~mm} \mathrm{Hg})$.

The pathogenesis of SIH is felt to be related to CSF hypovolemia, secondary to CSF leaking (usually at the cervicothoracic junction). ${ }^{1,10}$ Our patient developed symptoms immediately following neck stretching. A number of other cases have been associated with mild trauma or exercise. ${ }^{11-13}$ In our patient, it is possible trauma from the neck stretching led to a small tear in the dura and subsequent CSF leak. In SIH, the proposed mechanisms felt to be responsible for the headache include dilatation of cerebral or meningeal veins in response to the loss of CSF volume or traction on pain sensitive structures secondary to descent of the brain., 13,14 Compression of the diencephalon is presumed to be the mechanism causing coma. ${ }^{7}$

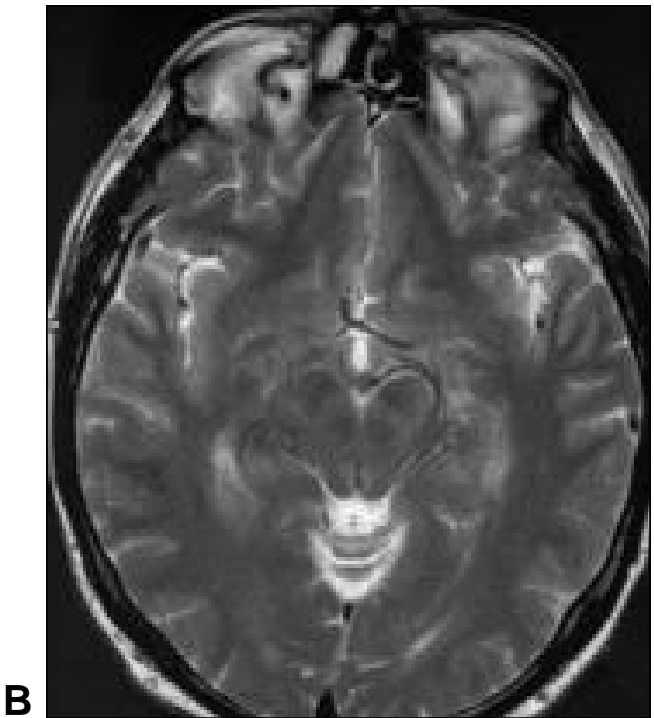

Figure 2b: Axial T2 weighted MRI. Six months after resolution of the symptoms and the brain stem compression is no longer present.

Small subdural fluid collections are common in SIH and likely arise as a compensation to the loss of CSF. ${ }^{1}$ The subdural hematoma in our patient was very small and lacked mass effect, thus it is unlikely that the subdural hematoma contributed to the clinical presentation.

If patients with SIH fail to improve with conservative

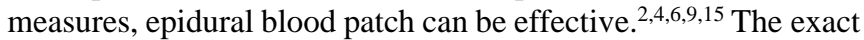
mechanism of epidural blood patches is still unknown. There are at least two possible mechanisms to explain the effectiveness. ${ }^{15-}$ ${ }^{18}$ The first proposes that coagulation of blood simply "seals" the leak. The second mechanism is thought to be an increase in epidural pressure which displaces CSF into the cranium increasing the pressure and impairing the caudal herniation of brain and spinal cord that is implicated in the pathogenesis of $\mathrm{SIH}$. There may also be both early and latent effects. ${ }^{19}$ The early effect results in displacement of the dura towards the cord that decreases the volume of CSF space and the latent effect is due to the "sealing" of the leak. It is reasonable that all the abovementioned mechanisms may contribute to the effectiveness of epidural blood patches.

Our patient had a dramatic response to epidural blood patches, which has been reported previously. ${ }^{9}$ In other previous case reports of patients with coma and SIH, multiple blood patches have been ineffective and treatment with intrathecal saline infusions and definitive surgical repair was required. ${ }^{7,8}$ Binder et $\mathrm{al}^{8}$ used intrathecal saline infusions titrated with the intracranial pressure to treat an intubated comatose patient who did not respond to initial lumbar epidural blood patches.

Patients who do not respond to blood patches require detailed neuroimaging (spinal MRI, CT myelography, radionuclide cisternography) to try and identify a leak..$^{2,7,8}$ We performed a spinal MRI and a technetium radionuclide scan that did not reveal any CSF leaks and since our patient responded so favorably to treatment we did not proceed with further invasive imaging. 
Spontaneous intracranial hypotension is an important new addition to the list of possible causes of coma. With timely recognition, treatments such as epidural blood patches and intrathecal saline infusions can produce dramatic and complete recoveries.

\section{REFERENCES}

1. Mokri B. Spontaneous cerebrospinal fluid leaks: from intracranial hypotension to cerebral spinal hypovolemia-evolution of a concept. Mayo Clin Proc 1999;74:1 113-1123

2. Spelle L, Boulin A, Tainturier C, et al. Neuroimaging features of spontaneous intracranial hypotension. Neuroradiology 2001; 43: 622-627.

3. Lin WC, Lirng JF, Fuh JL, et al. MR findings in spontaneous intracranial hypotension. Acta Radiologica 2002; 43: 249-255.

4. Pakiam AS, Lee C, Lang AE. Intracranial hypotension with parkinsonism, ataxia, and bulbar weakness. Arch Neurol 1999; 56(7): 869-872.

5. Hong M, Shah GV, Adams KM, Turner RS, Foster NL. Spontaneous intracranial hypotension causing reversible frontotemporal dementia. Neurology 2002; 58: 1285-1287.

6. Beck CE, Rizk NW, Kiger LT, et al. Intracranial hypotension presenting with severe encephalopathy. J Neurosurg 1998; 89(3): 470-473.

7. Pleasure SJ, Abosch A, Friedman J, et al. Spontaneous intracranial hypotension resulting in stupor caused by diencephalic compression. Neurology 1998; 50: 1854-1857.

8. Binder DK, Dillon W, Fishman RA, Schmidt MH. Intrathecal saline infusion in the treatment of obtundation associated with spontaneous intracranial hypotension: technical case report. Neurosurgery 2002; 51: 830-837.
9. Evans RW, Mokri B. Spontaneous intracranial hypotension resulting in coma. Headache 2002; 42:159-160.

10. Mokri B. The Munro-Kelly hypothesis: applications in CSF volume depletion. Neurology 2001; 56: 1746-1748.

11. Garcia-Albea E, Cabrera F, Tejeiro J, et al. Delayed post-exertional headache, intracranial hypotension, and racket sports. J Neurol Neurosurg Psych 1992; 55:975.

12. Schievink WI, Ebersold MJ, Atkinson JLD. Roller coaster headache due to spinal cerebrospinal fluid leak. Lancet 1996; 347: 1409.

13. Schoffer KL, Benstead TJ, Grant I. Spontaneous intracranial hypotension in the absence of magnetic resonance imaging abnormalities. Can J Neurol Sci 2002; 29: 253-257.

14. Rando TA, Fishman RA. Spontaneous intracranial hypotension: report of two cases and review of the literature. Neurology 1992; 42:481-487.

15. Waguri N, Tomita M, Hayatsu K, Okamoto K, Shimoji K. Epidural blood patch for treatment of spontaneous intracranial hypotension. Acta Anaesthesiol 2002; 46: 747-750.

16. Szeinfield M, Ihmeiden H, Moser MM, et al. Epidural blood patch: evolution of the volume and spread of blood injected into the epidural space. Anesthesiology 1986; 64: 820-822.

17. Kroin JS, Nagalla SKS, Buvanendran A, et al. The mechanisms of intracranial pressure modulation by epidural blood and other injectates in a post dural puncture rat model. Anesth Analg 2002; 95(2): 423-429.

18. Duff PJ, Crosby ET. The epidural blood patch. Resolving the controversies. Can J Anesth 1999; 46 (9): 878-886.

19. Sencakova, D, Mokri B, McClelland RL. The efficacy of epidural blood patch in spontaneous CSF leaks. Neurology 2001; 57: 1921-1923. 